\title{
Política FiSCAL E DESENVOLVIMENTO TECNOLÓGICO-EMPRESARIAL: UMA ANÁLISE CRÍTICA SOBRE INOVAÇÃO E TRIBUTAÇÃO
}

\author{
Fiscal policy and technological and business development: \\ a critical analyzes about innovation e taxation
}

\section{Paulo Caliendo}

Doutor em Direito Tributário pela PUC/SP. Mestre em Direito dos Negócios e bacharel pela Faculdade de Direito da UFRGS. Professor Titular na PUCRS, onde compõe o corpo permanente do Programa de Pós-Graduação em Direito, Mestrado e Doutorado, lecionando a disciplina de Direito Tributário. Professor de diversos cursos de Pós-Graduação no país. Autor do livro finalista do Prêmio Jabuti 2009, "Direito Tributário e Análise Econômica do Direito". Conselheiro do CARF, vice-presidente da Academia Tributária das Américas, árbitro da lista brasileira do Mercosul e Advogado. E-mail: caliendo@cedadvogados.com.br.

\section{Veyzon Muniz}

Mestrando e bacharel pela Faculdade de Direito da PUCRS Especialista em Direito Público, pela Escola Superior da Magistratura Federal no Rio Grande do Sul, e em Direito Tributário, pela Universidade Paulista. Pesquisador do Grupo de Pesquisas Avançadas em Direito Tributário (CNPq/PUCRS). Advogado e Técnico na Defensoria Pública do Estado do Rio Grande do Sul. E-mail: veyzon_muniz@yahoo.com.br

RECEBIDO EM: 03.05.2014

APROVADO EM: 17.07.2014

\section{Resumo}

O presente artigo tem por escopo analisar a inter-relação existente entre a política fiscal e o desenvolvimento tecnológico promovido com vista à sustentabilidade empresarial, centrando-se nos vetores inovação e tributação. Assim, partindo da premissa que as concepções de desenvolvimento e inovação não são alheias ao direito tributário por força constitucional, divide-se o estudo em três segmentos. No primeiro, analisa-se a noção de desenvolvimento e sua estruturação constitucional, centrando-se no estudo do desenvolvimento tecnológico e sua interface com a inovação empresarial. No segundo, expõe-se a relação entre a formulação da política fiscal e a promoção de desenvolvimento tecnológico-empresarial, explicitando-se experiências do direito comparado no campo do tratamento da inovação. No segmento final, traçam-se considerações sobre dois cases brasileiros (as normas sobre inovação 
tecnológica e o manejo da CIDE-Royalties) e seu impacto para o setor produtivo. Por conseguinte, assevera-se que, tomando por base o texto constitucional, sobremaneira, na previsão do desenvolvimento nacional enquanto objetivo fundamentalmente tem-se assegurada uma política tributária de fomento à inovação empresarial.

Palavras-chave: Política fiscal. Desenvolvimento. Inovação. TributaÇão.

\section{Abstract}

This article aims to analyze the interrelationship between fiscal policy and technological development promoted with a view to corporate sustainability, focusing on innovation and taxation vectors. Thus, on the premise that conceptions of development and innovation are not alien to the tax law by constitutional force, the study is divided into three segments. At first, we analyze the notion of development and its constitutional structure, focuses on the study technological development and its interface with business innovation. In the second, exposes the relationship between the formulation of fiscal policy and the promotion of business and technological development, explaining experiences of comparative law in the treatment field of innovation. At last segment, considerations are made about two Brazilian cases (the rules about technological innovation and the management of CIDE-Royalties) and his impact on the productive sector. Therefore, it is asserted that, based on the Constitution, reflects on the national development as fundamental objective, it has ensured a tax policy to foster business innovation.

Keywords: Fiscal policy. Development. Innovation. Taxation.

SumÁRIO: Introdução. 1. Estrutura constitucional de implementação do desenvolvimento. 2. Política fiscal, crescimento econômico e promoção do desenvolvimento. 3. Apontamentos acerca de cases brasileiros. Conclusão. Referências.

\section{INTRODUÇÃO}

A política fiscal pode e deve ser um mecanismo política de implementação do desenvolvimento. STIGLITZ (1998, p. 3) explicita que o desenvolvimento representa transformação social, constituindo-se como um movimento pelo qual as relações, formas e métodos tradicionais dão lugar a modos mais modernos de pensar e produzir. Adotando o desenvolvimento nacional como um objetivo fundamental, a Constituição Fundamental determina a busca pela mudança efetiva de um cenário 
social antiquado. Meta ao qual o direito não pode se furtar, sob pena se distanciar da realidade.

Nesse sentido, de pronto, lançando olhar sobre a tributação, fenômeno intersistêmico que congrega direito, política e econômica, se percebe que à instrumentação do direito tributário impõe-se a utilização de uma interpretação sistemática pela qual temáticas não ortodoxa e dogmaticamente previstas em sua análise "tradicional" passam a ter protagonismo. É esse o caso da tributação da inovação. A inovação, enquanto processo de otimização de recursos e competividade ao segmento empresarial, é passível de fomento através da formulação de uma política fiscal que possibilita crescimento e desenvolvimento econômico, revelando-se assim um rico campo de análise a um direito tributário "inovador".

Por conseguinte, o presente estudo desvela inter-relações existentes entre política fiscal e desenvolvimento tecnológico-empresarial, defendendo a fundamentalidade do estudo do direito tributário aplicado ao campo da inovação, com vista a uma melhor inteligência do desenvolvimento nacional constitucionalmente objetivado.

\section{Estrutura CONSTITUCIONAL DE IMPLEMENTAÇ̃̃o DO DESENVOLVIMENTO}

O desenvolvimento nacional é uma tarefa constitucional estabelecida entre os objetivos fundamentais da República em seu artigo $3^{\circ}$, bem como permeia todo o texto constitucional. O conceito de desenvolvimento nacional tem sido objeto de muitos debates na doutrina nacional, especialmente entre as correntes defensoras e contrárias ao ideário do desenvolvimentismo, que orientou toda a escola econômica cepalina.

Tal escola que teve a sua origem com a criação da Comissão Econômica para a América Latina e o Caribe (CEPAL), em 25 de fevereiro de 1948, influenciou fortemente a cultura nacional. Tratava-se de uma das cinco comissões econômicas regionais da Organização das Nações Unidas (ONU), tendo por objetivo o estudo e o monitoramento das políticas direcionadas à promoção do desenvolvimento econômico da região latino-americana. A ênfase em modelos intervencionistas de desenvolvimento econômico alimentou, assim, polêmicas sobre o sentido da expressão.

FURTADO (1974, p.75), na década de 1970, apontava que a ideia de desenvolvimento era um mito que se prestava a desviar as atenções da tarefa de identificação de necessidades fundamentais da coletividade e de possibilidades de avanço científico, para concentrá-las em objetivos abstratos como investimentos, exportações e crescimento. Entretanto, passados quarenta anos, após, o paradigmático advento constitucional, a concepção de desenvolvimento adotada no Brasil mostra-se mais concreta, estando de fato atrelada às finalidades precípuas de um Estado Democrático de Direito, constituindo-se tanto dos elementos abstratos clássicos quanto de efetivas demandas do segmento produtivo. 
Com efeito, o poder constituinte originário elevou o desenvolvimento nacional como objetivo fundamental expresso e, consequentemente, uma meta, em plano constitucional. A Constituição Federal de 1988 alterou o sentido de desenvolvimento presente no texto constitucional anterior que prescrevia o desenvolvimento econômico apenas como princípio da ordem econômica. O desenvolvimento passa de econômico para nacional e o seu alcance axiológico muda: de princípio da ordenação econômica passa a ser um objetivo constitucional fundamental.

Importante referir que o direito ao desenvolvimento foi adotado pela ONU (Declaração sobre o Direito ao Desenvolvimento de 1986) e observado pelo Brasil. O referido pacto definiu o desenvolvimento como "o constante incremento do bem - estar de toda a população e de todos os indivíduos com base em sua participação ativa, livre e significativa no desenvolvimento e na distribuição justa dos benefícios daí resultantes".

O direito ao desenvolvimento, como determinando no artigo $1^{\circ}$ da referida Declaração, estabelece alguns elementos característicos, quais sejam: i) multidimensionalidade: não se refere exclusivamente ao âmbito econômico, como inicialmente faria crer; ii) fundamentalidade: não se tratar de mera faculdade administrativa ou dever abstrato, uma vez que possui natureza de difusa, cuja titularidade é cada pessoa, um povo inteiro ou até mesmo um segmento produtivo; e iii) solidariedade: se contextualiza na busca conjunta de realização de um ambiente onde todas as liberdades fundamentais possam ser alcançadas por qualquer um. Sendo assim se trata de um verdadeiro comando normativo a ser buscado por toda a sociedade.

Importe atentar que, como bem aduzem VASCONCELLOS e GARCIA (1998, p. 205), o desenvolvimento nacional está ligado "as alterações da composição do produto e a alocação de recursos pelos diferentes setores da economia, de forma a melhorar os indicadores de bem-estar econômico e social". Nesses termos, na concepção de desenvolvimento percebe-se uma gama de segmentos diversos por ela abarcados.

Com base no texto constitucional, pode-se observar, nesse sentido, a opção por uma estruturação de implementação de modo especializado. Exemplo nítido da especialização do desenvolvimento nacional se dá no campo do desenvolvimento ambiental sustentável. FREITAS (2012, p. 42) aduz que o desenvolvimento material e imaterial, socialmente inclusivo, durável e equânime, ambientalmente limpo, inovador, ético e eficiente, é um princípio estruturante de nossa Carta Política. A noção de desenvolvimento sustentável aplicada à tutela ambiental encontra-se consagrada no artigo 225 da Constituição Federal, "no intuito de assegurar, preferencialmente de modo preventivo e precavido, no presente e no futuro, o direito ao bem-estar".

O desenvolvimento nacional sustentável encontra-se igualmente previsto no artigo $1^{\circ}$ da Lei n. 12.349 , de 15 de dezembro de 2010, que alterou o artigo $3^{\circ}$ da Lei de Licitações e estabeleceu que a licitação destina-se "a promoção do desenvolvimento nacional sustentável". Sendo o primeiro diploma legal brasileiro a trazer 
expressamente o termo.

De outra banda, o desenvolvimento tecnológico-empresarial, igualmente, é um prisma do desenvolvimento nacional sustentável objetivado pelo texto constitucional. Encara-se, nesse contexto, a inovação como o desenvolvimento de conhecimentos novéis aplicados a propósitos específicos, que se fazem "perceber através de novas técnicas, materiais ou equipamentos que aumentam a eficiência do processo produtivo ou que implicam em um novo ou aprimorado produto" 170 . Trata-se do desenvolvimento de novas tecnologias compatíveis pelas empresas com o imperativo de sustentabilidade. Visando atender tal segmento se estabelece uma verdadeira política constitucional de incentivo à inovação, como se observa nas referências ao desenvolvimento tecnológico e econômico do país (artigo $5^{\circ}$, inciso XXIX), nas políticas agrícola (artigo 187, inciso III), de saúde (artigo 200, inciso V) e educacional (artigos 207, $\S 2^{\circ}$ e 214, inciso V) e, sobremaneira, no Capítulo IV, da Ciência e Tecnologia. ${ }^{171}$

Outrossim, discorrendo sobre inovação tecnológica, competição internacional e os desafios da tributação internacional da renda, GRAETZ e DOUD (2013, pp. 348-9) afirmam:

Two things are clear and essentially uncontested among economists. First is the importance of technological innovations to economic growth. [...] Second, research and development (" $R \& D$ "), which is crucial to ongoing technological advances, [...] In addition to spurring innovation, $R \& D$ also creates good jobs and raises standards of living. ${ }^{172}$

Destarte, filia-se a proposição de que as inovações tecnológico-empresariais são de extremo relevo ao crescimento econômico, bem como de que a pesquisa e desenvolvimento são fundamentais para os avanços tecnológicos e para a elevação dos padrões de vida geral. Ocorre que a atividade inovadora fomenta a transforma-

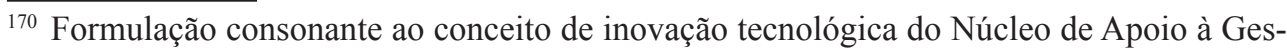
tão da Inovação da Pontifícia Universidade Católica do Rio Grande do Sul - PUCRS.

171 Atenta-se ainda que: "A política de estímulo à inovação englobará ainda o estímulo e apoio à formação de recursos humanos nas áreas de ciência, pesquisa e tecnologia, bem como irá estimular que elas ocupem meios e condições especiais de trabalho. Em especial a lei apoiará e estimulará as empresas que invistam em pesquisa, criação de tecnologia adequada ao País, formação e aperfeiçoamento de seus recursos humanos e que pratiquem sistemas que assegurem ao empregado, desvinculada do salário, participação nos ganhos econômicos resultantes da produtividade de seu trabalho" (CALIENDO, 2012, p. 148).

172 Tradução livre: "Duas coisas são claras e, essencialmente, incontestáveis entre os economistas. A primeira é a importância das inovações tecnológicas para o crescimento econômico. A segunda, pesquisa e desenvolvimento (P\&D), que são fundamentais para os avanços tecnológicos em curso, além de estimular a inovação, também criam bons empregos e eleva os padrões de vida".
} 
ção do conhecimento científico em produtos, processos e serviços que dão causa ao desenvolvimento tecnológico nacional. ${ }^{173}$

O direito constitucional subordina as interações com o capital estrangeiro ao interesse nacional de promoção do desenvolvimento nacional, evitando as tentações do protecionismo e da discriminação nacional. Determina o artigo 172 da Constituição Federal, inclusive, que, com base no interesse nacional, a lei deve disciplinar, os investimentos de capital estrangeiro, incentivar os reinvestimentos e regular a remessa de lucros.

Em consonância ao raciocínio de COOTER, SHÄFER e TIMM (2007, p. 59), é interessante perceber que a inovação nasce, geralmente, em ambiente privado. Assim, é previamente a publicização da informação ou ideia privadas que deve ocorrer a formulação de políticas estatais (como p.ex. a política fiscal) que atendam as demandas públicas por e decorrentes da evolução tecnológica. Em outros termos, deve-se ter a ciência de que a inovação surge no âmbito de uma estratégia de mercado pela qual o agente privado se diferencia dos seus concorrentes e maximiza seus lucros. Sob esse prisma de análise, pressupondo-se que com a disseminação da nova ideia, tecnologia ou procedimento e, consequente, estabilização dos interesses dos agentes concorrentes, a tutela estatal do processo de inovação, com vista ao desenvolvimento tecnológico deve se constituir no fornecimento de infraestrutura jurídica e física às atividades inovadoras. ${ }^{174}$

Por conseguinte, cabe ponderar que, em certos segmentos, os elevados cus-

173 SARLET e MOLINARO (2012, p. 36) aduzem que "a visão do desenvolvimento tecnológico como um processo sistemático, não apenas sujeito às leis físicas, mas resultado da definição e escolha de valores específicos das pessoas envolvidas neste processo abre novos espaços para o controle e o direito regulamentar".

174 Explicita-se o posicionamento dos autores: "Um inovador descobre uma nova ideia e usa esse conhecimento privado para obter lucros extraordinários. Os concorrentes acabam descobrindo o que o inovador sabe e a ideia se torna pública. À medida que a informação se torna pública, o inovador reduz seu lucro a um nível normal. Porque inovação começa com informação privada, é imprevisível conhecê-la antecipadamente; mas, quando se torna pública, passa a ser compreensível. Esses fatos têm consequências para o direito e para as políticas públicas que geram desenvolvimento econômico. Para evitar corrupção, funcionários públicos que formulam as políticas públicas de investimento devem se valer, para a tomada de decisões, apenas de informações públicas. Esses funcionários, entretanto, não podem prever quais empresas ou quais ramos industriais terão rápido crescimento. Isso exigiria informação privada. Consequentemente, é improvável que políticas públicas que promovem o desenvolvimento por meio do investimento privado tenham sucesso. Países ricos confiam fundamentalmente no setor privado como o motor do crescimento. Nesses países, o Estado garante o desenvolvimento indiretamente, por meio do fornecimento de infraestrutura jurídica e física. A melhor opção para países ricos também é a melhor para países menos ricos. Infelizmente, alguns políticos e intelectuais acreditam que os países em desenvolvimento são exceções que exigem direcionamento da economia. Nessas situações, o Estado poderia oferecer mais, sendo menos ambicioso". 
tos ou riscos dos negócios impõem uma forte atuação pública que funciona como um redutor dos custos de transação ou como promotor de externalidades positivas. Todavia, em outras situações, a intervenção estatal pode ser amplificador de externalidades negativas, no sentido de desincentivar a inovação, mantendo monopólios ou estruturas burocráticas desnecessárias. Logo, a efetividade do desenvolvimento tecnológico-empresarial está imbrincada com a análise consequencial dos agentes econômicos que o manejam.

\section{Política fiscal, CRescimento econômico e promoção do deSenvolvi- MENTO}

A política fiscal é um instrumento macroeconômico que se presta a definir o orçamento público, englobando, dentre outros aspectos, o poder estatal de arrecadação (definição e recolhimento de tributos). São de sensível importância, assim, a observância e a compatibilidade da utilização desse instrumento com o objetivo desenvolvimentista (Cf. MUNIZ, 2013).

Uma vez que é pela tributação que o Estado consegue financiar gastos púbicos - o que é fundamental para a sua saúde econômica -, a política fiscal tem um efeito de multiplicador sobre a economia interna: quando expansionista leva a aumento do PIB real do país, quando contracionista leva a queda do mesmo indicador. No corolário, a movimentação dessa política pública influi diretamente nos elementos abstratos de avaliação do país, mas também no bem-estar real de sua população e saúde financeira das empresas. Logo, afirma-se que a formulação de bases tributárias, enquanto políticas públicas, não deve apenas tentar fazer cumprir as prioridades que decorrem da demanda arrecadatória, devendo atender ao interesse público de desenvolvimento socioeconômico. A atuação extrafiscal do Estado nesse campo possui um forte elemento de externalidades positivas, desde que respeitando determinados limites e princípios como legalidade, igualdade e livre concorrência.

Com efeito, no Brasil, quando se trata da tributação da inovação, há uma política pública constitucionalmente protegida, que se insere no âmbito de atuação promocional do Estado Democrático de Direito, de incentivar a solução dos problemas brasileiros por meio do desenvolvimento do sistema produtivo nacional e regional (CALEINDO, 2012, p. 170). ${ }^{175}$ Dessa sorte, é inegável a complexa relação existente entre a tributação e inovação, sobremaneira, no que tange ao binômio: for-

\footnotetext{
175 Situação característica desses problemas é a mortalidade das empresas. O segmento empresarial, como agente de desenvolvimento, deveria gozar de larga longevidade. Todavia, a taxa de sobrevivência de empresas de dois anos, a partir de dados estimados pela Receita Federal (SEBRAE, 2013), corresponde a 75,6\%, ou seja, a cada 100 empresas criadas no país, após dois anos, aproximadamente 24 já terão fechado as portas. A burocracia (sobretudo, na seara tributária) é um dos fatores que dão causa a esse cenário. Porém, quando se trata de desenvolvimento tecnológico, esse status quo deve ser diferente, sob pena de se ver desatendido o texto constitucional.
} 
mulação da política tributária e fomento à inovação empresarial. Assim, faz-se importante observar a perspectiva comparada para se estabelecer uma melhor avaliação da experiência brasileira.

Tomando-se, inicialmente, o caso da União Europeia, se percebe que a colaboração tecnológica entre Estados pode ser rastreada desde os anos 1980, sendo feita, a partir da década seguinte, uma séria consideração acerca do tratamento fiscal das inovações tecnológicas. Percebe-se a partir da prática europeia que há um problema inevitável na política fiscal (interna), qual seja: os avanços tecnológicos (de escala global) se desenvolvem mais rapidamente do que a legislação tributária, ensejando corriqueiramente em barreiras ao investimento e a competitividade empresarial.

ANDREOSSO-O'CALLAGHAN (2000, p. 14) aponta que os europeus, cientes desse fato, desenvolveram então uma política de inovação mais abrangente na União Europeia, o que resultou no Action Plan for Innovation in Europe (Plano de Ação para Inovação na Europa), em 1996. Fez-se, assim, recomendações por alterações fiscais, no plano interno, necessárias ao desenvolvimento tecnológico integral da União Europeia. Em linhas geais, os regimes fiscais, especialmente, as sistemáticas de tributação da renda, passaram ser orientadas para a promoção da mobilidade de investigadores e para o desenvolvimento de esquemas de stock option ${ }^{176}$.

Espanha e Portugal são exemplos de países que em há benefícios fiscais para as despesas de inovação tecnológica das grandes empresas. Já os países mais inovadores, como Alemanha, países nórdicos e Reino Unido, apresentam menores índices, o que se explica pelo tratamento fiscal preferencial e diferenciado concedido à alta tecnologia importada (em detrimento da de origem nacional). Nesse sentido, observa-se que os países europeus buscam atualizar sua estrutura produtiva através, de um lado, do investimento direto na atividade privada e, de outro, na atração de investimentos externos para o segmento inovador.

Pode-se dizer que o tratamento tributário favorável ao desenvolvimento tecnológico na maior parte dos países da União Europeia fica atrás dos Estados Unidos. Entretanto, a despeito de tentativas de introdução de incentivos fiscais para a inovação pela via legislativa, temos no Reino Unido a Finance Bill (de 2000 com previsões nesse sentido até hoje) ${ }^{177}$ e na França a Lei sobre Inovação e Pesquisa (vigente desde 1999). ${ }^{178}$

\footnotetext{
176 Plano de opção de compra de ações cedidas gratuitamente pela empresa aos seus empregados.

177 YIU (2012) aduz que a prioridade para formuladores de políticas públicas britânicos é remover barreiras e apoiar as empresas inovadoras que possuem aspirações e potencial para alcançar um rápido crescimento econômico.

${ }^{178} \mathrm{O}$ diploma prevê a mobilidade de pesquisadores nos campos industrial e empresarial, a cooperação entre o setor público e privado na área de pesquisa e desenvolvimento e, especificamente em matéria tributária, alterações na legislação geral de impostos francesa (artigos $4^{\circ}$ e $\left.8^{\circ}\right)$.
} 
Por sua vez, observando o caso norte-americano, como referem KRUGLIANSKAS e MATIAS-PEREIRA (2005, p. 1019), temos a experiência de políticas de intervenção no mercado tecnológico no sentido de conceder elevados incentivos à acumulação e aplicação de capital privado na área. Segundo HALL (2001, p. 22), nos Estados Unidos existe relativamente poucos benefícios fiscais específicos relacionados com a inovação, vigendo um sistema cuja preferência não é pela concessão de créditos fiscais para as atividades inovadoras e sim pela desoneração de impostos.

Esta ausência de benefícios fiscais próprios para a inovação tecnológico -empresarial é motivo de certa preocupação para algumas multinacionais, que buscam cada vez mais posicionar suas atividades de pesquisa e desenvolvimento em lugares do mundo em que encontrem custos mais baixos. Nesse sentido, na seara das relações internacionais, percebe-se o alinhamento da formulação de políticas fiscais preocupadas com o estabelecimento de regimes fiscais favoráveis a um ambiente de atração de empresas atuantes na pesquisa e desenvolvimento. ${ }^{179}$

Entretanto, tem-se no baixo percentual do imposto sobre ganhos de capital o principal instrumento tributário de promoção de atividades inovadoras nos Estados Unidos, o que se presta a compensar o segmento empresarial dos riscos que correm ao atuarem no ramo. Um fato interessante é que o já baixo percentual de $28 \%$ foi reduzido ainda mais na década de noventa, o que acarretou no nítido desenvolvimento tecnológico norte-americano nos anos $2000 .^{180}$

Essa situação tem ampliado o debate sobre qual o instrumento mais adequado ao desenvolvimento tecnológico-empresarial: uma ampla gama de desonerações fiscais para todos os setores econômicos (intervenção horizontal) ou o recurso

179 Discorre a pesquisadora: "This absence of innovation-related tax incentives is in fact of some concern to large U.S. multinationals, who find it increasingly easier to locate their R\&D and other activities wherever in the world they find that costs are lower. Several of them have pointed to the current $R \& D$ tax provisions as important in a world where other countries are offering them even more favourable tax treatment in order to attract their R\&D. However, the most important tax incentive in the United States for innovative activities is probably not R\&E tax credit, but is the low tax rate on capital gains, which partly compensates entrepreneurs and venture capitalists for the risk they bear. It is this rather than the credit that encourages entrepreneurial activity and leads to the continuous entry of new firms and technologies onto the market. An interesting fact is that the already low rate of $28 \%$ was lowered even further in 1998, and the effects of that increased incentive are probably only just beginning to be felt" (HALL, 2001).

${ }^{180}$ Imperioso destacar que, se um primeiro olhar, a política tributária de incentivo ao desenvolvimento tecnológico é tímida, o fomento à inovação nos Estados Unidos se concretiza no "uso do poder de compra do Estado em favor de produtores locais (Buy American Act). Além dessa legislação o governo utiliza um amplo e generoso programa de financiamento a fundo perdido pra o desenvolvimento tecnológico de pequenos e microempresários (Small Business Innovactive Reaserch - SBIR)"'. (Cf. KRUGLIANSKAS e MATIAS-PEREIRA, 2005, p. 1019). 
a desonerações a setores específicos selecionadas por órgãos governamentais (intervenção vertical). Tanto uma medida quanto a outra possuem vantagens e desvantagens, contudo, o princípio da neutralidade concorrencial tende a indicar que somente em casos residuais é que a ação estatal deva ser justificada.

Ainda sob o signo do direito comparado, faz-se mister referir que, no âmbito do desenvolvimento e inovação, a Organização para a Cooperação e Desenvolvimento Econômico (OCDE), que tem por atribuição institucional a proposição de condutas adequadas (boas práticas) a partir da troca de experiências no intuito de orientar as ações governamentais (políticas públicas), possui notório destaque. Em estudos produzidos sobre a inter-relação entre tributação e inovação (PALAZZI, 2011), os seus membros são orientados à adoção de políticas fiscais que, significativamente, forneçam incentivos tributários eficientes à inovação, eis que ela é motor de competitividade entre empresas e que desempenha um papel fundamental no desenvolvimento sustentável e no crescimento econômico.

\section{Apontamentos acerca de cases brasileiros}

Se o texto constitucional é imperativo no que tange ao objetivo fundamental de desenvolvimento, a realidade empresarial ainda é bastante carente. A implementação de medidas tributárias voltadas ao atingimento do desenvolvimento tecnológico-empresarial mostra-se bastante tímida, sobretudo, quando se tem ciência dos cenários comparados.

BARBOSA (2011, p. 570-1) leciona que as normas tributárias acerca do estímulo à produção de tecnologia, antes do advento da Constituição Federal de 1988, limitavam-se tão somente à possibilidade de certas deduções de investimentos em pesquisas promovidas por pessoas jurídicas no âmbito do imposto sobre a renda (IRPJ), constantes nas Leis n. 7.232/1984 (primeira Lei da Informática) e n. 7.646/1987 (Lei do Software). Tratava-se de um modelo similar ao norte-americano.

Destarte, com a diretriz constitucional de promoção e incentivo ao desenvolvimento científico e tecnológico, novas normas foram editadas, como p.ex., a Lei n. 8.661/1993 que previa incentivos fiscais aos Programas de Desenvolvimento Tecnológico Industriais (PDTI) e Agrapecuários (PDTA). Todavia, como bem referem KRUGLIANSKAS e MATIAS-PEREIRA (2005, p. 1019), é somente com a aprovação da Lei de Inovação Tecnológica (LIT), em 2 de dezembro de 2004, e sua regulamentação, que o Brasil passou a contar com um instrumento normativo de fomento à inovação e à pesquisa científica e tecnológica.

Em verdade, a partir da LIT foram criados incentivos fiscais à inovação tecnológico-empresarial no país, sendo assim responsável por um certo avanço legislativo sobre a tributação da inovação. O escopo legislativo é o incremento do nível científico, da pesquisa e da inovação no âmbito empresarial e, consequentemen- 
te, fortalecer o desenvolvimento nacional, sobremaneira, no setor industrial. ${ }^{181}$ Nessa linha, o artigo 28 da LIT prevê expressamente que "a União fomentará a inovação na empresa mediante a concessão de incentivos fiscais".

A Lei de Incentivo à Inovação (LII) ou Lei do Bem, por sua vez, em 21 de novembro de 2005, a partir da conversão da MPv n. 255/2005, estabeleceu incentivos fiscais instituídos em cumprimento ao referido artigo da LIT, instituindo ainda o Regime Especial de Tributação para a Plataforma de Exportação de Serviços de Tecnologia da Informação (REPES), o Regime Especial de Aquisição de Bens de Capital para Empresas Exportadoras (RECAP) e o Programa de Inclusão Digital.

Dentre os incentivos reais previstos na LII destinados à pesquisa, desenvolvimento e inovação nas empresas, com usufruto de forma automática, destacamse (MCTI, 2013, pp. 8-9):

a) Exclusão do lucro líquido e da base de cálculo da contribuição social sobre o lucro líquido (CSLL), o valor correspondente de até $60 \%$ da soma dos dispêndios, classificados como despesas operacionais pela legislação do IRPJ, realizados com pesquisa e desenvolvimento no ano base considerado;

b) Adição de até $20 \%$, no caso de incremento do número de pesquisadores dedicados exclusivamente à pesquisa e desenvolvimento contratados no ano de referência;

c) Adição de até $20 \%$, na soma dos dispêndios ou pagamentos vinculados à pesquisa tecnológica e desenvolvimento de inovação tecnológica objeto de patente concedida ou cultivar registrado.

d) Redução de 50\% do IPI na compra de máquinas, equipamentos, aparelhos e instrumentos (nacionais ou importados) destinados ao uso exclusivo de pesquisa tecnológica e desenvolvimento de inovação tecnológica;

e) Redução à zero da alíquota do imposto de renda incidente sobre as remessas ao exterior destinadas aos pagamentos de registro de manutenção de marcas, patentes e cultivares;

f) Depreciação acelerada integral, sem prejuízo da depreciação normal dos equipamentos, máquinas, aparelhos e instrumentos no próprio período de aquisição, destinados à pesquisa, desenvolvimento e inovação para fins de IRPJ e CSLL;

g) Dedução do saldo não depreciado dos equipamentos, máquinas, aparelhos e instrumentos destinados à pesquisa, desenvolvimento e inovação, no

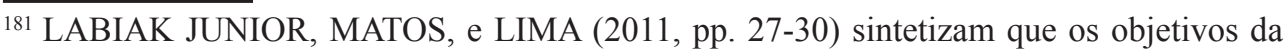
LIT, abarcados em seu artigo $1^{\circ}$, correspondem ao estabelecimento de medidas de incentivo à inovação e à pesquisa científica no ambiente produtivo, com vistas à capacitação e ao alcance da autonomia e desenvolvimento tecnológicos, nos termos dos artigos 218 e 219 da Constituição Federal. 
ano em que for concluída a sua utilização;

h) Amortização acelerada (dedução) dos dispêndios relativos à aquisição de bens intangíveis destinados à pesquisa, desenvolvimento e inovação, no ano base;

i) Dedução do saldo não amortizado dos dispêndios relativos à aquisição de bens intangíveis destinados à pesquisa, desenvolvimento e inovação, no ano em que for concluída a sua utilização;

j) Exclusão, para efeito de apuração do IRPJ e da CSLL, de 50\% a 250\% dos dispêndios efetivados em projetos de pesquisa científica e tecnológica executada por instituição científica e tecnológica (ICT), cuja operacionalização é executada sob a gestão da Coordenação de Aperfeiçoamento de Pessoal de Nível Superior (CAPES).

Com efeito, a LII, mediante esses incentivos está na linha de frente da promoção da inovação, conferindo autonomia e possibilidades de incremento produtivo do mercado interno. Ela se constitui em um instrumento na afirmação da soberania nacional nos segmentos de pesquisa e desenvolvimento. ${ }^{182}$

Todavia, a efetividade dos incentivos fiscais legalmente previstos é ainda baixa. O último Relatório Anual da Utilização dos Incentivos Fiscais (MCTI, 2013, p. 27) refere que "o número de empresas que aderiram ao usufruto dos incentivos fiscais do Capítulo III da Lei do Bem comprova que continua em plena ascensão. Com efeito, em relação ao ano de 2011, o aumento registrado foi da ordem de $8 \%$, ou seja, de 972 empresas cadastradas em 2011 passou para 1.042 empresas em 2012". Demonstrando-se, assim, que mesmo crescente, ainda é tímida a efetiva adesão do empresariado a essa política pública, não havendo, igualmente, dados sobre o número de patentes geradas, empregos, faturamento ou crescimento do market share (quota de mercado) destas empresas.

Outra norma de impacto no desenvolvimento tecnológico-empresarial é a Lei n. 10.168, de 30 de dezembro de 2000, que instituiu uma contribuição de intervenção no domínio econômico devida pela pessoa jurídica detentora de licença de uso ou adquirente de conhecimentos tecnológicos, bem como aquela signatária de contratos que impliquem transferência de tecnologia, firmados com residentes ou domiciliados no exterior. Com ela nascia a CIDE-Royalties ou CIDE-Tecnologia que seria regulamentada em 11 de abril de 2002, pelo Decreto n. 4.195/2002, com o fulcro no financiamento do Programa de Estímulo à Interação Universidade-Em-

${ }^{182}$ ARAÚJO (2010, p. 3) faz consideração importante: "Os estímulos à inovação na forma de incentivos fiscais se tornaram, nos últimos anos, uma tendência internacional. Ainda que estejam longe de serem perfeitos, estes incentivos apresentam algumas vantagens que os tornam atraentes para os formuladores de política: i) são baseados em alocações de mercado, uma vez que o processo decisório sobre o desenvolvimento da inovação e o montante do gasto cabe à firma; ii) não discriminam setores; e iii) estão prontamente disponíveis às empresas, com baixo custo administrativo para o governo." 
presa para Apoio à Inovação, “cujo objetivo principal é estimular o desenvolvimento tecnológico brasileiro, mediante programas de pesquisa científica e tecnológica cooperativa entre universidades, centros de pesquisa e o setor produtivo" (artigo $1^{\circ}$ da Lei n. 10.168/2000).

Nos termos do artigo 10 do decreto regulamentador, a CIDE-Royalties incide sobre as importâncias pagas, creditadas, entregues, empregadas ou remetidas, a cada mês, a residentes ou domiciliados no exterior, a título de royalties ou remuneração, previstos nos respectivos contratos, que tenham por objeto: fornecimento de tecnologia, prestação de assistência técnica, serviços técnicos e de assistência administrativa e semelhantes, cessão e licença de uso de marcas, e cessão e licença de exploração de patentes.

Tributam-se, assim, as referidas hispóteses com vista a angariar recursos para que o Estado promova e incentive o desenvolvimento científico, a pesquisa e a capacitação tecnológicas, nos termos do artigo 218 da Constituição Federal. ${ }^{183}$ A imposição, nesses termos, atua como um desestímulo à aquisição de tecnologia estrangeira e a sua substituição por fornecedores nacionais, não sujeitos à incidência desse tributo.

A CIDE-Royalties cuja arrecadação advém da incidência de alíquota de $10 \%$ sobre a remessa de recursos ao exterior para pagamento de assistência técnica, royalties, serviços técnicos especializados ou profissionais, é destinada integralmente ao Fundo Nacional de Desenvolvimento Científico e Tecnológico (FNDCT), vinculado ao Ministério da Ciência, Tecnologia e Inovação (MCTI) e executado pela Financiadora de Estudos e Projetos (FINEP) e pelo Conselho Nacional de Desenvolvimento Científico e Tecnológico (CNPq). É, justamente, no âmbito desse fundo que se insere o Programa de Estímulo à Interação Universidade-Empresa para Apoio à Inovação.

Com efeito, para garantir investimentos permanentes na pesquisa científica e tecnológica do Brasil, criaram-se fundos setoriais para os seguintes setores: aero-

\footnotetext{
${ }_{183}$ Destaca-se que: “[...] a CIDE-royalties poderia ser entendida como uma falsa CIDE, visto que ela objetiva instituir o Programa de Estímulo à Interação Universidade-Empresa para o Apoio à Inovação e estimular o desenvolvimento tecnológico brasileiro, mediante programas de pesquisa científica e tecnológica cooperativa entre universidades, centros de pesquisa e o setor produtivo. [...] Tal entendimento, contudo, não implica necessariamente que o mercado de tecnologia e informação não seja considerado como setor econômico e igualmente composto por agentes econômicos em regime de competição e que as normas de proteção à ordem econômica são sejam aplicáveis ao mesmo. O texto constitucional elevou esses setores estratégicos ao nível de proteção social na distribuição de seus resultados sociais, realçando um dos elementos mais fortes da Ordem Econômica: assegurar a todos uma existência digna, conforme os ditames da justiça social e da função social da propriedade em regime de mercado" (CALEINDO, 2012, pp. 161-2).
} 
náutico ${ }^{184}$, agronegócio ${ }^{185}$, biotecnologia ${ }^{186}$, saúde ${ }^{187}$ e de educação superior ${ }^{188}$. No exercício de 2012, cada um dos fundos arrecadou, respectivamente, $\mathrm{R} \$ 94.994 .807$, $\mathrm{R} \$ 221.654 .550, \mathrm{R} \$ 94.994 .807, \mathrm{R} \$ 221.654 .550$ e $\mathrm{R} \$ 633.298 .715$, totalizando $\mathrm{R} \$$ 1.266.597.429 arrecadados pela contribuição social que onera o segmento produtivo, segundo dados do próprio MCTI.

Percebe-se, desse modo, que a CIDE-Royalties se mostra um mecanismo tributário de impacto relevante no setor de pesquisa e desenvolvimento, gerando uma receita derivada expressiva (mais de um bilhão de reais) que, em tese, deve ser revertida para os segmentos que podem ser considerados estratégicos ao desenvolvimento nacional. Assim, se, de um lado, a imposição tributária em análise se constitui como uma significativa fonte de receitas a ser destinada (ou revertida) ao desenvolvimento tecnológico-empresarial, de outro, não existem comprovações, por dados oficias, devidamente discriminados, acerca do montante do valor repassado

${ }^{184}$ Fundo para o Setor Aeronáutico que tem por escopo estimular investimentos em pesquisa e desenvolvimento no setor com vistas a garantir a competitividade nos mercados interno e externo, buscando a capacitação científica e tecnológica na área de engenharia aeronáutica, eletrônica e mecânica, promover a difusão de novas tecnologias, a atualização tecnológica da indústria brasileira e maior atração de investimentos internacionais para o setor. 7,5\% do arrecadado pela contribuição são destinados a esse fundo.

${ }^{185}$ Fundo Setorial de Agronegócio que tem por escopo estimular a capacitação científica e tecnológica nas áreas de agronomia, veterinária, biotecnologia, economia e sociologia agrícola, promover a atualização tecnológica da indústria agropecuária, com introdução de novas variedades a fim de reduzir doenças do rebanho e o aumento da competitividade do setor; estimular à ampliação de investimentos na área de biotecnologia agrícola tropical e de novas tecnologias. 17,5\% do arrecadado pela contribuição são destinados a esse fundo.

${ }^{186}$ Fundo Setorial de Biotecnologia que tem por escopo promover a formação e capacitação de recursos humanos; fortalecer a infraestrutura nacional de pesquisas e serviços de suporte; expandir a base de conhecimento da área; estimular a formação de empresas de base biotecnológica e a transferência de tecnologias para empresas consolidadas; realizar estudos de prospecção e monitoramento do avanço do conhecimento no setor. 7,5\% do arrecadado pela contribuição são destinados a esse fundo.

${ }^{187}$ Fundo Setorial de Saúde Estimular a capacitação tecnológica nas áreas de interesse do SUS (saúde pública, fármacos, biotecnologia, etc.), aumentar os investimentos privados em pesquisa e desenvolvimento, promover a atualização tecnológica da indústria brasileira de equipamentos médico-hospitalares, difundir novas tecnologias que ampliem o acesso da população aos bens e serviços na área de saúde. $17,5 \%$ do arrecadado pela contribuição são destinados a esse fundo

${ }^{188}$ Fundo Verde Amarelo que tem por escopo incentivar a implementação de projetos de pesquisa científica e tecnológica cooperativa entre universidades, centros de pesquisa e o setor produtivo; estimular a ampliação dos gastos em pesquisa e desenvolvimento realizados por empresas; apoiar ações e programas que reforcem e consolidem uma cultura empreendedora e de investimento de risco no país. $50 \%$ do arrecadado pela contribuição são destinados a esse fundo. 
efetivamente a ações concretas tão pouco se prevê uma avaliação da eficácia desses fundos setoriais.

Por todo exposto, assevera-se que o maior problema à inovação no Brasil encontra-se justamente no sistema tributário, pesado e complexo, que desestimula o empreendedorismo no país. Questões básicas não encontram soluções em nosso sistema: a tributação do comércio eletrônico, dos royalties, do ágio e das transferências internacionais são sintomáticas. Esses aspectos geram elevada incerteza (custos de transação) e um elevado custo financeiro e de cumprimento das normas (externalidades) e, assim, mesmo com normas de incentivo, percebe-se um ambiente de negócios muito desfavorável aos empreendedores tecnológicos.

\section{Conclusões}

i) O desenvolvimento nacional é um processo evolutivo e fragmentário, constitucionalmente alçado ao patamar de objetivo republicano, que conjuga o crescimento da economia e a paralela maximização de bem-estar social. Especializado pelo texto da Constituição Federal, o avanço da ciência e da tecnologia do país deve ser catalisado pela formulação de políticas de incentivo a atividades empresariais inovadoras vinculadas ao imperativo de sustentabilidade. Assim, a formulação de políticas públicas de promoção da inovação tecnológico-empresarial gozam, indubitavelmente, de constitucionalidade e interesse social.

ii) Entendendo-se a sustentabilidade como princípio constitucional estruturante que viabiliza a concretização do objetivo fundamental de desenvolvimento, tem a constatação da inter-relação existente entre política fiscal e desenvolvimento tecnológico-empresarial. A política tributária de fomento à inovação promovida com vista à sustentabilidade empresarial, permite a garantia da sustentabilidade fiscal (pública) e da sustentabilidade empresarial (privada), de modo integrado.

iii) As políticas de incentivo são meios primordiais para se alcançar o desenvolvimento. A partir das proposições de SEN (2000, p. 25-6), tem-se que oportunidades sociais, que facilitem a participação econômica, e facilidades econômicas (na forma de efetiva inserção no mercado), que ajudem na geração de lucro privado e, consequentemente, de recursos públicos à concretização de direitos fundamentais, são indispensáveis a formulação de políticas de incentivo. Em uma perspectiva de promoção, no campo da ciência e da tecnologia, a inovação deve ser objeto tanto de oportunidades sociais quanto de facilidades econômicas.

iv) A tributação da inovação é uma política pública constitucionalmente protegida, que se insere no âmbito de atuação promocional de um Estado Democrático de Direito. Assim, a política fiscal deve objetivar a eliminação de barreiras ao investimento e a competitividade empresariais. Na União Europeia, observa-se a existência de benefícios ao setor privado com experiências de incentivos fiscais para a inovação. Já nos Estados Unidos, temos uma política integral de fomento à 
atividade inovadora, que em matéria tributária se centra na redução de impostos. No âmbito da OCDE, orienta-se a adoção de políticas fiscais que forneçam incentivos tributários eficientes à empresas inovadoras, objetivando o crescimento econômico.

v) Ao Brasil incube estruturar um melhor modelo de política fiscal aplicada ao desenvolvimento tecnológico-empresarial. Entendendo-se que a construção de um conjunto encadeado e coerente de mecanismos tributários de promoção à inovação é indispensável para se atingir o desenvolvimento nacional. Nesse sentido, os instrumentos tributários analisados, em ambos os cases (as normas sobre inovação tecnológica e o manejo da CIDE-Royalties), em análise puramente normativa, são positivos para a pesquisa, desenvolvimento e inovação do país, todavia, em face de análise empírica, se mostram incipientes e carentes de avaliações detalhadas de seus resultados efetivos ao segmento produtivo.

\section{REFERÊNCIAS}

ANDREOSSO-O'CALLAGHAN, Bernadette. Taxation and innovation in the European Union. In: Korean Journal of EU Studies, vol. 5, n. 1. Fairfax: REUS, 2000.

ARAÚJO, Bruno C. Incentivos fiscais à pesquisa e desenvolvimento e custos de inovação no Brasil. In: Revista Radar, n. 9. Brasília: IPEA, 2010.

BARBOSA, Denis Borges. Direito de inovação: comentários à lei federal de inovação, incentivos fiscais à inovação, legislação estadual e local, poder de compra do Estado (modificações à lei de licitações). Rio de Janeiro: Lumen Juris, 2011.

Biblioteca Virtual de Direito Humanos da Universidade de São Paulo. Declaração sobre o Direito ao Desenvolvimento de 1986. Disponível em: http:/www.direitoshumanos.usp.br/index.php/Direito-ao-Desenvolvimento/declaracao-sobre-o-direito-ao-desenvolvimento.html. Acessado em: 22.10.2013.

BRASIL. Constituição da República Federativa do Brasil de 1988, de 05 de outubro de 1988. Disponível em: http://www.planalto.gov.br/ccivil_03/constituicao/constituicao.htm. Acessado em: 20.03.2013.

. Decreto $n$. 4.195, de 11 de abril de 2002. Disponível em: http://www. planalto.gov.br/ccivil_03/decreto/2002/D4195.htm. Acesso em: 22 out. 2013.

. Lei n. 10.168, de 29 de dezembro de 2000. Disponível em: http://www. planalto.gov.br/ccivil_03/leis/110168.htm. Acesso em: 22 out. 2013.

Lei $n$. 10.973, de 02 de dezembro de 2004. Disponível em: http://www. planalto.gov.br/ccivil_03/_ato2004-2006/2004/1ei/110.973.htm. Acesso em: 22 out. 2013.

. Lei n. 11.196, de 21 de novembro de 2005. Disponível em: http://www. 
planalto.gov.br/ccivil_03/_ato2004-2006/2005/lei/111196.htm. Acesso em: 22 out. 2013.

. Lei n. 12.349, de 15 de dezembro de 2010. Disponível em: http://www. planalto.gov.br/ccivil_03/_Ato2007-2010/2010/Lei/L12349.htm. Acessado em: 22.10.2013.

CALIENDO, Paulo. Tributação da inovação: observações da inovação. In: SAAVEDRA, Giovani; LUPION, Ricardo. (orgs.) Direitos fundamentais: direito privado e inovação. Porto Alegre: EdiPUCRS, 2012.

CANOTILHO, J. J. Gomes; MENDES, Gilmar F.; SARLET, Ingo W.; STRECK, Lênio L. (coords.). Comentários à Constituição do Brasil. São Paulo: Saraiva, 2013.

COOTER, Robert; SCHÃFER, Hans-Bernd; TIMM, Luciano Benetti. Direito e desenvolvimento: qual é a melhor política pública para o Estado dirigir o desenvolvimento? In: Revista da Faculdade Mineira de Direito, vol. 10, n. 20. Belo Horizonte: PUC Minas, 2007.

FRANÇA. LOI no 99-587 du 12 juillet 1999 sur l'innovation et la recherche. Disponível em: http://www.legifrance. gouv.fr/affich Texte.do? cidTexte=JORFTEXT000000759583\& dateTexte $=\&$ categorieLien $=\mathrm{id}$. Acessado em: 10.02.2014.

FREITAS, Juarez. Sustentabilidade: direito ao futuro. 2 ed. Belo Horizonte: Fórum, 2012.

FURTADO, Celso. O mito do desenvolvimento econômico. São Paulo: Círculo do Livro, 1974.

GRAETZ, Michael J.; DOUD, Rachel. Technological innovation, international competition, and the challenges of international income taxation. In: Columbia Law Review, vol. 113:347. Nova Iorque: Columbia Law School, 2013.

HALL, Bronwyn H. Tax incentives for innovation in the United States. In: USA Innovation Tax Incentives (BHH Draft). Berkeley: UC, 2001.

KRUGLIANSKAS, Isak; MATIAS-PEREIRA, José. Um enfoque sobre a Lei de Inovação Tecnológica do Brasil. In: Revista de Administração Pública, vol. 39, n. 5. Rio de Janeiro: FGV, 2005.

Ministério da Ciência, Tecnologia e Inovação, MCTI. Relatório Anual da Utilização de Incentivos Fiscais: Ano Base 2012. Disponível em: http://www.mct.gov.br/upd_blob/0229/ 229781.pdf. Acessado em: 12.12.2013.

Fundo Nacional de Desenvolvimento Cientifico e Tecnológico-FNDT. Disponível em: http://www.mct.gov.br/index.php/content/view/725.html. Acessado em: 02.02.2014. 
MUNIZ, Veyzon Campos. Política externa sustentável: um conceito possível? In: Mundorama, v. 75. Brasília: UNB, 2013.

PALAZZI, Pamela. Taxation and Innovation. In: OECD Taxation Working Papers, n. 9. Paris: OECD, 2011.

Pontifícia Universidade Católica do Rio Grande do Sul, PUCRS. Núcleo de Apoio à Gestão da Inovação. Disponível em: http://www3.pucrs.br/portal/page/portal/inovapucrs/Capa/ NAGI/Inovacao. Acessado em: 22.10.2013.

SARLET, Ingo W.; MOLINARO, C. A. "Não existe o que panoramicamente vemos no céu": o ponto-cego do direito (política públicas sobre regulação em ciência e tecnologia). In: SAAVEDRA, Giovani; LUPION, Ricardo. (orgs.) Direitos fundamentais: direito privado e inovação. Porto Alegre: EdiPUCRS, 2012.

SEN, Amartya Kumar. Desenvolvimento como liberdade. Trad. Laura Teixeira Motta. São Paulo: Companhia das Letras, 2000.

Serviço Brasileiro de Apoio às Micro e Pequenas Empresas, SEBRAE. Coleção de estudos e pesquisas - julho de 2013; Sobrevivencia das empresas no Brasil. Disponível em: http://bis.sebrae.com.br/GestorRepositorio/ARQUIVOS_CHRONUS/ bds/bds.nsf/93772f4f62b0716c573d3a9ed5a6a3aa/\$File/4456.pdf. Acessado em: 08.08.2013.

STIGLITZ, Joseph. Towards a new paradigm for development: strategies, policies, and processe. Genova: UNCTAD, 1998.

VASCONCELOS, Marco Antonio; GARCIA, Manuel Enriquez. Fundamentos de economia. São Paulo: Saraiva, 1998.

YIU, Chris. Financing Innovation: supporting early stage, aspirational and growing businesses. In: Research Note: March 2012. Londres: Police Exchange, 2012. 